\title{
Produção de hortaliças orgânicas: estudo de caso em uma propriedade do interior de ljuí, RS
}

\author{
Organic vegetable production: a hopeful initiative in the \\ interior in ljuí, RS, countryside
}

Producción de hortalizas orgánicas: e una iniciativa esperanzada en el interior de ljuí, RS

Luana Carvalhaes Coutinho ${ }^{1}$ Jana Koefender ${ }^{2}$

Claudia Prudencio De Mera ${ }^{3}$ Juliane Nicolodi Camera ${ }^{4}$

\footnotetext{
${ }^{1}$ Mestranda em Desenvolvimento Rural Sustentável pela Universidade de Cruz Alta (UNICRUZ). Bacharel em Agroecologia pelo Instituto Federal do Sudeste de MG - Campus Rio Pomba. E-mail: luana14carvalhaes@hotmail.com, Orcid: http://orcid.org/0000-0001-5780-3195

${ }^{2}$ Doutorado em Agronomia. Docente permanente do Mestrado Profissional em Desenvolvimento Rural e do curso de Agronomia na Universidade de Cruz Alta (UNICRUZ).E-mail: jkoefender@unicruz.edu.br, Orcid: http://orcid.org/0000-0002-5882-9669

${ }^{3}$ Doutorado em Desenvolvimento Rural. Docente permanente do Mestrado Profissional em Desenvolvimento Rural e do Programa de Pós-Graduação em Práticas Socioculturais e Desenvolvimento Social - Mestrado, Universidade de Cruz Alta (UNICRUZ).E-mail: cmera@unicruz.edu.br, Orcid: http://orcid.org/0000-0001-5293-3054

${ }^{4}$ Doutorado em Agronomia. Docente permanente do Mestrado Profissional em Desenvolvimento Rural e do curso de Agronomia na Universidade de Cruz Alta (UNICRUZ). E-mail: ju_camera@yahoo.com.br, Orcid: http://orcid.org/0000-0001-7182-5788
} 
Resumo: O crescimento do mercado de produtos orgânicos vem gerando o interesse de agricultores familiares. Estudos são necessários para avaliar o sistema orgânico nesse contexto. O objetivo foi analisar o sistema produtivo orgânico em uma pequena propriedade rural do município de ljuí, RS. Foi realizado um estudo de caso descritivo e qualitativo, com uma família de agricultores que tem entre as suas atividades agrícolas, a produção orgânica de hortaliças. O instrumento de coleta de dados foi a observação direta e uma entrevista, a fim de analisar as práticas utilizadas no sistema de produção. Discorre, também, sobre os desafios e o confrontamento que os agricultores abordam sobre o sistema, observado na propriedade. A produção de hortaliças é ainda pequena, mas as práticas hoje aplicadas favorecem os sistemas de produção orgânica. Verifica-se também a participação da mulher no sistema produtivo, que atua na mudança de paradigmas e sendo responsável por decisões e a comercialização da produção.

Palavras-chaves: agroecologia; agricultura familiar; sustentabilidade.

\begin{abstract}
The growth of the market of organic products has generated the interest of family farmers. Studies are needed to evaluate the organic system in this context. The objective was to analyze the organic production system in a small rural property in the county of Ijuí, RS. A descriptive and qualitative case study was carried out, with a family of farmers who have among their agricultural activities the organic production of vegetables. The instrument of data collection was the direct observation and an interview, in order to analyze the practices used in the production system. It also discusses the challenges and confrontation that farmers address about the system, observed in the property. The production of vegetables is still small, but the practices applied today favor the systems of organic production. The participation of women in the productive system, which acts in the paradigm shift and is responsible for decisions and the commercialization of production, is also verified.
\end{abstract}

Keywords: agroecology; family agriculture; sustainability.

Resumen: El crecimiento del mercado de productos orgánicos viene generando el interés de agricultores familiares. Los estudios son necesarios para evaluar el sistema orgánico en este contexto. El objetivo fue analizar el sistema productivo orgánico en una pequeña propiedad rural del municipio de ljuí, RS. Se realizó un estudio de caso descriptivo y cualitativo, con una familia de agricultores que tiene entre sus actividades agrícolas, la producción orgánica de hortalizas. El instrumento de recolección de datos fue la observación directa y una entrevista, a fin de analizar las prácticas utilizadas en el sistema de producción. También discurre, los desafíos y la confrontación que los agricultores abordan sobre el sistema, observado en la propiedad. La producción de hortalizas aún pequeña, pero las prácticas hoy aplicadas favorecen los sistemas de producción orgánica. Se verifica también la participación de la mujer en el sistema productivo, que actúa en el cambio de paradigmas y siendo responsable por decisiones y la comercialización de la producción.

Palabras claves: agroecologia; agricultura familiar; sostenibilidad. 


\section{INTRODUÇÃO}

Com o constante crescimento da população mundial, a produção agrícola precisa estar em constante crescimento seja em volume de produção de alimentos como em qualidade, entretanto o uso abusivo de agrotóxicos causa a intoxicação de animais, do ambiente e dos seres humanos. A preocupação em relação aos impactos negativos dos agroquímicos na atividade agrícola vem crescendo significativamente. Situações de intoxicação em seres vivos e danos ao meio ambiente ocorrem primordialmente na vida de trabalhadores rurais que fazem o uso desses produtos. De acordo com Carvalho, Ponciano e Souza (2016), trabalhadores de baixa renda, produtores marginais ou assalariados são os grupos que mais sofrem intoxicação por agrotóxicos. Barros (2010) também relata que a manipulação inadequada dos produtos, principalmente por parte dos trabalhadores rurais, contribui para a contaminação.

Por outro lado, princípios agroecológicos têm viabilizado a produção de alimentos com o uso saudável e responsável dos recursos naturais, precavendo a degradação e a contaminação destes, e contribuindo para o desenvolvimento sustentável.

Com a agroecologia, é possível produzir alimentos e conduzir a propriedade rural de maneira sustentável, uma vez que esta respeita os recursos naturais, sem torná-los escassos e degradados. A agroecologia tem contribuído para novas perspectivas para viabilizar a produção, que, além de direcionar ao caminho da sustentabilidade econômica, social, preserva o meio ambiente.

Foi na década de 1970 que a agricultura orgânica surgiu no Brasil, emergindo como uma alternativa ao uso dos agrotóxicos. O produtor com selo orgânico, além de garantir bom preço de seus produtos, pelos modos que são cultivados, se sobressai ainda nos requisitos da segurança alimentar e proteção ao meio ambiente.

Pode-se dizer que há um consenso dos benefícios ambientais e sociais da produção orgânica, no entanto, há uma relutância no que tange aos aspectos econômicos e técnicos, por parte dos produtores.

Na região de abrangência do presente estudo, predominam a produção em áreas extensivas de soja, milho e trigo. Não obstante isso, 
nessas culturas o uso de agrotóxicos é elevado para a obtenção de altas produtividades. Pequenas áreas de agricultura familiar acabam à mercê do agronegócio dessas commodities e se está em busca de alternativas que possibilitem a sustentabilidade econômica, ambiental, social e também a segurança alimentar de suas famílias. Apesar dos inúmeros estabelecimentos de agricultura familiar, são escassas as pesquisas que abordem o processo produtivo na agricultura orgânica na região.

Dentro desse contexto, o presente trabalho objetivou analisar o sistema produtivo orgânico em uma pequena propriedade rural do município de ljuí, RS.

\section{MATERIAL E MÉTODOS}

O presente artigo utilizou como modalidade de pesquisa, o estudo de caso descritivo e qualitativo. Segundo Yin (2005), o uso do estudo de caso é muito utilizado quando se quer investigar algo empírico no qual se envolve um fenômeno contemporâneo dentro do contexto da vida real; desperta-se ainda mais quando os limites entre o fenômeno e os contextos não estão pré-definidos. A coleta de dados foi realizada em agosto de 2017, com uma família de agricultores de uma pequena propriedade rural localizada no interior do município de ljuí, RS, e que tem, entre as suas atividades agrícolas, a produção orgânica. O estudo compreendeu apenas uma família, em virtude de ser a única no município que está atualmente produzindo alimentos com base orgânica, isto é, em fase de transição do sistema convencional de produção para o orgânico. Os instrumentos de coleta de dados foram a observação direta da unidade de produção, no intuito de investigar os métodos utilizados no cultivo das plantas e uma entrevista semiestruturada com a família. A observação permite obter resultados de modo indutivo e dialógico, ou seja, os informantes podem participar na discussão das conclusões obtidas à medida que a observação prossegue e as interpretações começam a ser desenvolvidas pelo pesquisador (ANGROSINO, 2009). 


\section{REVISÃO DE LITERATURA}

Em virtude de o Brasil ser um dos maiores usuários de agrotóxico do mundo, a ocorrência de intoxicações e de outras doenças tem se dado especialmente entre os trabalhadores rurais, mas também os que consomem alimentos contaminados não ficam de fora do risco da contaminação (PIGNATI, 2011). Devido a esses fatos, a busca por alimentos isentos de agrotóxicos se torna algo preponderante na vida de consumidores, que não deixam de adquiri-los por conta do preço mais alto que um alimento convencional e acreditam ser um investimento na saúde e melhoria do meio ambiente.

Para Altiere (2012), é importante para o produtor rural ter como foco a eliminação de agroquímicos, adequando-se a mudanças no manejo da sua propriedade; da importância de preferir as fontes orgânicas de nutrientes e um manejo integrado de pragas. Cabe assim, ao produtor entender que práticas sustentáveis são possíveis, basta apenas dar o primeiro passo à mudança.

Segundo Penteado (2012), a agricultura orgânica baseia-se na proteção do meio ambiente, na qual o uso dos recursos naturais deve ser adequado. Umas das vantagens que ele cita é a produção de alimentos saudáveis, evitando a contaminação dos seres humanos e da natureza.

A produção orgânica exige que o produtor tenha paciência, empenho e muita dedicação, uma vez que os cultivos e os processos de produção demandam um tempo diferente em relação ao cultivo convencional, principalmente em relação ao controle de pragas e doenças. Além disto, vislumbra-se o equilíbrio ecológico, através da manutenção de plantas bem nutridas, o que diminui a incidência de moléstias. Nesse sistema, é valorizada a relação do solo com a planta e o ambiente (MEIRELLES; RUPP, 2005). Os recursos naturais de cada propriedade rural necessitam ser valorizados, reconhecidos e corretamente usados. Se apenas extraídos, não mantidos e protegidos, coloca-se em risco a funcionalidade do sistema.

A área de produção orgânica vem se expandindo. No final de 2014, ela foi estimada em 43,7 milhões e aumentou para 50,9 milhões de hectares em 2015, incluindo cerca de 2,4 milhões de produtores (IFOAM, 2017). Há cerca de 15 mil propriedades certificadas ou que estão em processo de 
transição, e destas 75\% pertencem a agricultores familiares. O Brasil ocupa o segundo lugar de maior produtor da América Latina, destacando-se os estados do Paraná, São Paulo, Rio Grande do Sul, Minas Gerais e Espírito Santo, que juntos somam 70\% da produção brasileira (SERVIÇO BRASILEIRO DE APOIO ÀS MICRO E PEQUENAS EMPRESAS [SEBRAE], 2010). E segundo dados do Instituto de Pesquisa Economia Aplicada (FERNANDES JR., 2005), a demanda por produtos orgânicos vem expandindo, cerca de $30 \%$ anualmente. Destaca-se, nesse contexto, o papel dos agricultores familiares, pois são atores responsáveis por $90 \%$ da produção orgânica no país.

No Rio Grande do Sul, estado no qual a propriedade locus deste estudo está localizada, ainda é predominante a área com lavouras de monocultivos com o uso de agrotóxicos, como trigo, milho e soja principalmente. Segundo Ortiz (2012), o Brasil ocupa o primeiro lugar no ranking do consumo de agrotóxicos no mundo há pelo menos três anos. Já Cigana (2013) ressalta que o estado do Rio Grande do Sul chegou a quase o dobro da média nacional no que se refere ao seu uso. Salienta que dados da safra de 2009/2010 despertaram a atenção pelo uso de 85 milhões de litros de agrotóxicos no Rio Grande do Sul, equivalente a 34 piscinas cheias de químicos. O gaúcho, a cada ano, faz em média o uso de 8,3 litros de veneno; e em 2011, a média do país ficou representada por 4,5 litros por habitante.

Por outro lado, a busca por produtos mais saudáveis no Rio Grande do Sul vem aumentando significativamente nos últimos anos, segundo dados da EMATER/RS de 2013, mencionados por Mariani e Henkes (2015), 100 municípios gaúchos possuem suas feiras com base ecológica. A aquisição por produtos orgânicos se dá em feiras livres, cujos preços são mais acessíveis do que aos produtos encontrados no mercado.

Quanto ao mercado de produtos orgânicos, a procura por esses alimentos está crescendo. As taxas passam de $20 \%$ ao ano, segundo registros do projeto Organics Brasil (2015). O índice foi de 25\% em 2015 e agora deve passar de $30 \%$. Além das feiras e comércios simples que vendem produtos orgânicos, as grandes redes de varejo estão se interessando no comércio. Como por exemplo, as duas maiores redes de supermercados no Brasil - Pão de Açúcar e Carrefour, segundo a Associação Brasileira de Supermercados (SOCIEDADE NACIONAL DE AGRICULTURA [SNA], 2016). 
Outro fator relevante é a importância de o consumidor de alimentos agrícolas conhecer um pouco da produção do alimento que está adquirindo, uma vez que resíduos de compostos químicos aplicados no campo podem estar presentes na feira de muitos comerciantes. Carneiro et al. (2011), confirmam que a análise realizada pela ANVISA em 2011, testemunhou alimentos com contaminação e resíduos de agrotóxicos além do permitido.

Diante da eventualidade da contaminação de agrotóxicos sobre alimentos, é que a segurança alimentar vem se alicerçando. A prática agroecológica envolve também em seus princípios a segurança alimentar. Salienta a importância do direito que as pessoas têm de estabelecer suas estratégias tanto na produção de alimentos como no consumo referente à sua necessidade (MALUF; REIS, 2013).

\section{ANÁLISE E DISCUSSÃO DOS DADOS}

\subsection{Descrição da unidade de produção rural}

A Unidade de produção rural estudada está localizada na comunidade conhecida como "Alto da União" distante 12 km do centro do município de Ijuí, onde reside a dez anos uma família composta por um casal de agricultores. Anteriormente eram moradores da área urbana, onde ela exercia a atividade de doméstica e ele de pedreiro. Contudo sempre almejaram adquirir uma propriedade rural, pois os dois tinham vivido grande parte da infância no meio rural e tinham conhecimento sobre os benefícios da produção de alimentos de forma sustentável. Relataram que, quando residiam na zona urbana, sentiam falta de ter uma área para produzir pelo menos alguns alimentos para subsistência.

Embora a área de terra adquirida seja de um hectare, a atividade agrícola com a produção de hortaliças vem se consolidando nos últimos anos. Além disto, a maioria das hortaliças é de ciclo curto, o que favorece uma produção mais intensiva em pequenos espaços. Dentre as hortaliças produzidas, estão repolho, alface, couve-folha, beterraba, mostarda, morango, plantas condimentares e medicinais (Figura 1). 
Figura 1 - Policultivo realizado na propriedade (alface, repolho, morango e alho)
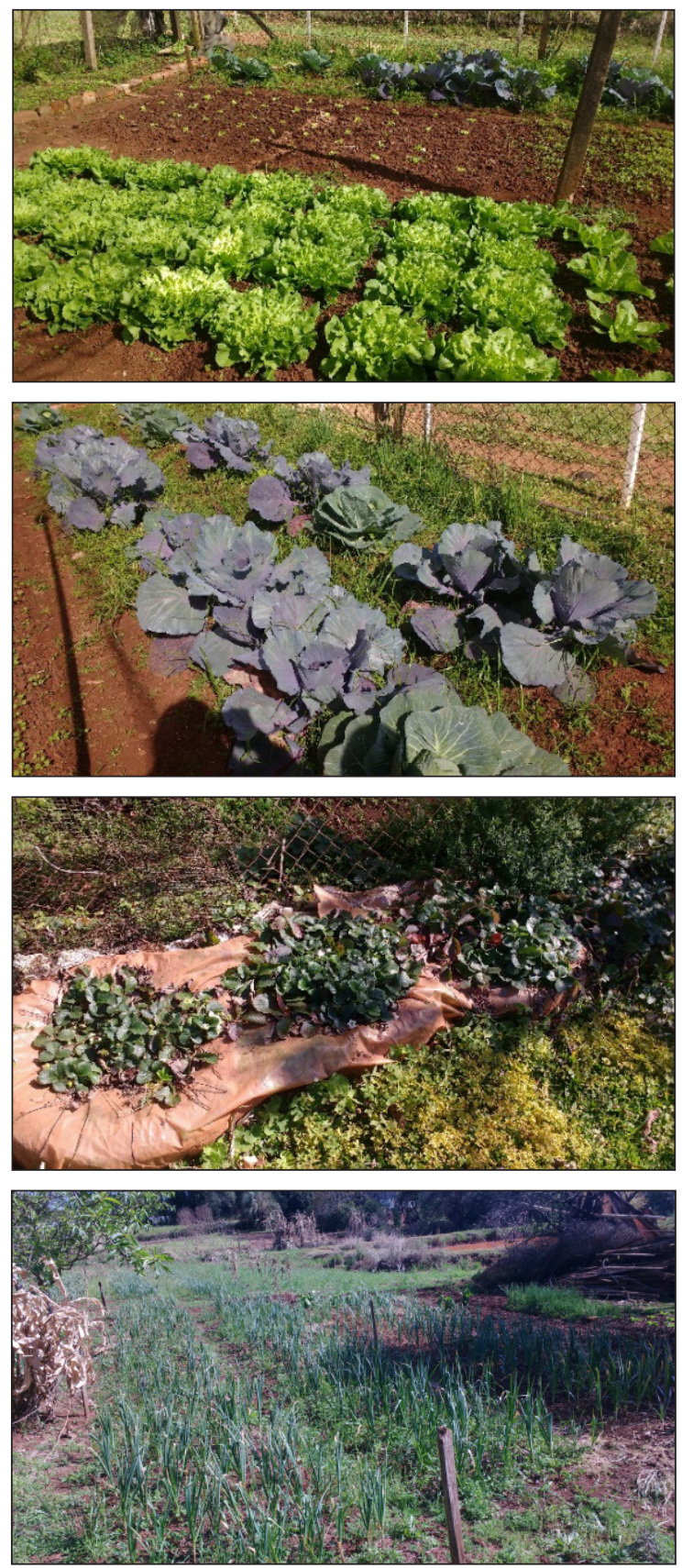

Fonte: Elaborado pelas autoras. 
Segundo relato dos agricultores, o estímulo de mudança para a produção com base nas práticas agroecológicas advém do fato do amplo uso de agrotóxicos na região, principalmente dos arredores. Além disto, mencionam que a dependência de insumos agrícolas externos à propriedade também fez com que planejassem a mudança de sistema de cultivo, reduzindo dessa forma os custos de produção.

Além do já exposto, relataram a preocupação com a saúde dos envolvidos nas atividades rurais e dos consumidores, o que também fortaleceu o propósito de mudança na produção.

Também se verificou que são produzidos na propriedade suínos, bovinos de leite e aves, sendo todos para subsistência da família.

Abordaram que o próximo passo será a comercialização das hortaliças na feira que acontece na zona urbana, todas as terças e quintas-feiras. Atualmente são comercializadas para os consumidores locais próximos, na própria propriedade, e também nos arredores, onde a agricultora circula com o carro oferecendo sua produção aos demais moradores da localidade. Segundo a agricultora, os gastos com a atividade produtiva são apenas com a compra de sementes, algumas mudas (a maioria é produzida no local), manutenção do sombrite e custo com energia elétrica que movimenta a água para irrigação das olerícolas.

O esposo é funcionário assalariado exercendo atividade fora da propriedade, como capina, consertos de cerca, limpeza de açudes, alimentação do gado e outros, sendo esta considerada a principal fonte de renda familiar. Uma segunda fonte de renda se dá pela comercialização dos produtos orgânicos, que, embora os agricultores não sobrevivessem apenas desta, mas, segundo eles, já auxilia como um "ganho extra". Ambos têm a expectativa de permanência no meio rural, uma vez que buscam por alternativas e estão no processo de mudança de sistema de produção, aumentando a diversidade na produção de plantas e animais. Vale ressaltar que os proprietários demonstram um apreço pelo local, o que auxilia no processo transitório. Godinho (2015) desperta a necessidade de todos os envolvidos no negócio trabalharem conjuntamente na busca de melhores alternativas para atingir suas metas, para isto, um bom planejamento, fundamentado em dados e informações de qualidade precisa ser priorizado. Contudo é importante 
salientar que no momento o casal de agricultores não apresenta condições econômicas e viabilidade técnica para iniciar um processo de certificação, bem como a unidade de produção não é vinculada a nenhuma associação ou cooperativa. Sobretudo, a produção já atende alguns requisitos gerais dos sistemas orgânicos de produção como a implementação de policultivos, o manejo sustentável do solo e o mínimo do uso de insumos externos.

\subsection{Viabilidade técnica de manejo}

Quando se discute produção de orgânicos, é imprescindível avaliar a viabilidade técnica de produção. No caso estudado, boa parte da mão de obra requerida na horta, como a preparação de canteiros, manutenção da cobertura morta e demais atividades da produção de hortaliças, é realizada pela mulher. No ramo da agricultura familiar, entende-se que cada vez mais a mulher se destaca. Para Siliprandi (2015), a mulher na produção familiar desenvolve sistemas mais agroecológicos nas suas atividades agrícolas, seja na atividade vegetal ou animal, pois ela se preocupa com a qualidade dos alimentos destinados à sua família. Pesquisa realizada por Karam (2004) com agricultoras em Curitiba, PR, apresenta que o papel da mulher tem sido representativo, pois no mínimo em $50 \%$ das unidades pesquisadas foram as mulheres que assumiram as primeiras responsabilidades quanto à conversão do sistema de produção convencional para o orgânico e que assumiram decisão pelos 'primeiros riscos' na conversão, iniciando a instalação e preparação de pequenas hortas nos arredores da casa, sendo também responsáveis pela comercialização, semelhante ao verificado na presente pesquisa. As atividades desenvolvidas na propriedade recebem a assistência técnica da EMATER-ASCAR/RS.

Sobretudo, sabe-se que produzir orgânicos requer muito empenho e tempo de trabalho. A maior parte do tempo consumido nessa propriedade se dá particularmente na capina manual. É comum se deparar com várias espécies de plantas espontâneas que dominam a área rapidamente, caso não haja um manejo adequado. Para Sediyama et al. (2010), no manejo de plantas espontâneas não deve ser utilizada apenas a capina, a busca por métodos permitidos na produção de alimentos livres de químicos deve ser 
alcançada. É muito comum o uso de cobertura morta, uma vez que seja uma técnica de fácil execução, consegue-se aproveitar diferentes resíduos orgânicos, até mesmo o capim e uma série de materiais vegetais alternativos.

Os insumos utilizados são provenientes da própria unidade de produção, como o esterco bovino que é destinado para adubação das hortaliças. Lima et al. (2011) ressaltam que todo recurso local da propriedade deve ser utilizado, bem como os subprodutos orgânicos para o fornecimento de nutrientes, devendo-se ainda realizar a ciclagem de nutrientes utilizando restos culturais, resíduos orgânicos e ainda adubos verdes como as leguminosas.

Verificou-se que a irrigação é realizada utilizando-se um poço artesiano, e as mudas são produzidas em bandejas de poliestireno.

Em relação à produção de mudas, no cultivo orgânico todo cuidado e seguimento das respectivas orientações legalizadas devem ser rigorosamente efetuadas.

Trabalhos têm apontado a possibilidade da utilização de diversos materiais alternativos como substrato seja de origem animal, como esterco e húmus de minhoca (SANTOS et al., 2010), ou vegetal, casca de arroz, bagaços, serragem, fibra ou pó de casca de coco (SILVA et al. 2010; LÜDKE et al., 2008). No presente estudo, observou-se que utilizam uma mistura de esterco com solo.

Toda área cultivada com hortaliças apresenta uma ampla diversidade de plantas com porte e raízes diferentes, o que contribui para um ambiente equilibrado e a presença de inimigos naturais que auxiliam no controle biológico.

Uma técnica de manejo também muito utilizada no sistema orgânico é a adubação com adubos verdes. Na propriedade estudada, a principal fonte de adubação é o esterco bovino, e não se observou a utilização de adubos verdes. Santos, Sediyama e Pedrosa (2013) salientam a importância das leguminosas, como adubos verdes que, quando cultivadas e incorporadas ao solo, garantem vida e nutrição às plantas. Muitas espécies podem trazem benefícios ao sistema, porém o cuidado na escolha das espécies de adubo verde é muito importante, pois para cada tipo de clima, solo e manejo das plantas haverá uma espécie de melhor resultado. Uma recomendação de alerta que o mesmo autor faz, é que o uso de adubos verdes em consórcio 
com hortaliças requer cuidados, como o porte das plantas e a época de plantio da leguminosa, em relação ao da cultura, evitando a competição. A prática do uso de adubos verdes como leguminosas poderia ser uma das técnicas que adotadas na propriedade para melhoria das condições físicas e químicas do solo, e dessa forma contribuir com a sustentabilidade do sistema.

Quando se pensa em estabilidade de produção, a rotação de culturas é um tipo de técnica muito adotada. Essa técnica, além de dar estabilidade a produção, dá ao produtor maior seguridade quando, por exemplo, uma determinada cultura se torna propensa. Logo, ele não tem em mãos uma única cultura, mas sim uma gama de plantas que garantem tranquilidade e recursos financeiros em funcionamento. Além dessas vantagens, assegura colheitas escalonadas, podendo também permitir ao produtor obter uma renda adicional (SANTOS; CARVALHO, 2013).

Já no manejo de pragas e doenças, existem hoje várias alternativas de produtos comerciais orgânicos no mercado. O uso de plantas repelentes e armadilhas são práticas fáceis e que apresentam resultados satisfatórios, entretanto verificou-se que os agricultores não fazem uso de nenhuma técnica no controle alternativo. Souza (2014) realizou uma pesquisa associando o cultivo de manjericão com a cultura do pimentão, na qual verificou que a presença do manjericão reduziu significativamente a população de pulgões sem afetar a produção. Além de plantas repelentes e iscas, o uso de armadilhas luminosas para controle de insetos também pode ser usado, seja armadilha de cor ou com feromônios, iscas e até controle mecânico (SOUZA; REZENDE, 2003; VENZON et al., 2010).

Quanto aos aspectos econômicos, verificou-se que não há um controle nos custos de produção, ainda havendo necessidade de aprimoramento de gestão. Segundo Barros, Monteiro e Prado (2011), é de suma importância visualizar a propriedade rural como um negócio voltado para a geração de renda. Mas vale ressaltar que a atividade de produção orgânica tem fortalecido os aspectos ambientais e de sustentabilidade alimentar da família, sendo o excedente comercializado, e dessa forma gerando renda. 


\section{CONSIDERAÇÕES FINAIS}

A preocupação com a saúde e bem-estar dos agricultores e consumidores tem aumentado, e a redução no uso de agrotóxicos se faz necessária. A produção orgânica visa muito mais do que simplesmente as questões econômicas da produção, é um processo produtivo que almeja garantir a saúde dos seres humanos e preservação dos recursos naturais, respeitando a cultura local e os conhecimentos tradicionais e seguir no caminho da sustentabilidade.

No presente estudo, observou-se a produção de hortaliças ainda pequena, mas as práticas hoje aplicadas favorecem os sistemas de produção, e o processo transitório da agricultura tradicional para a orgânica e com a produção de hortaliças é favorecido. Este artigo descreve o movimento desse processo, as práticas utilizadas que seguem os princípios da agroecologia e o caminho trilhado para o estabelecimento da unidade produtiva orgânica.

Destaca-se também o papel da mulher no sistema produtivo, atuando como um sujeito social que atua na mudança de paradigmas, tomando decisões e ocupando um espaço geralmente masculino. Assim, cabe aos pesquisadores e técnicos, em parceria com os agricultores, fortalecer esse movimento na construção de uma agricultura mais sustentável.

\section{REFERÊNCIAS}

ALTIERI, M. Agroecologia: bases científicas para uma agricultura sustentável. Rio de Janeiro: AS-PTA, 2012.

ANGROSINO, M. Etnografia e observação participante. Porto Alegre, RS: Artmed, 2009.

BARROS, K. A. Estudo químico-quântico do potencial carcinogênico de agrotóxicos. 2010. 74 f. Dissertação (Mestrado em Química) - Universidade Federal de Pernambuco (UFPE), Recife, 2010. Disponível em: https://repositorio.ufpe.br/ bitstream/123456789/8968/1/arquivo941_1.pdf. Acesso em: 11 jul. 2018.

BARROS, C.; MONTEIRO, A. L. G.; PRADO, O. R. O gerenciamento da empresa rural. Milkpoint, São Paulo, fev. 2011. Disponível em: http://www.farmpoint.com.br/ radares-ecnicos/gerenciamento/o-gerenciamento-daempresa-rural-69847n.aspx. Acesso em: 5 maio 2018. 
CARNEIRO, F. F.; ALMEIDA, V. E. S.; TEIXEIRA, M. M.; BRAGA, L. Q. V. Agronegócio e agroecologia: desafios para a formulação de políticas públicas sustentáveis. In: RIGOTTO, R. (Org.). Agrotóxicos, trabalho e saúde - vulnerabilidade e resistência no contexto da modernização agrícola no Baixo Jaguaribe/CE. Fortaleza: Universidade Federal do Ceará, 2011. p. 584-612.

CARVALHO, C. R. F.; PONCIANO, N. J.; SOUZA, C. L. M. Levantamento dos agrotóxicos e manejo na cultura do tomateiro no município de Cambuci-RJ. Revista Ciência Agrícola, Maceió, AL, v. 14, n. 1, p. 15-28, 2016. Disponível em: http://www.seer. ufal.br/index.php/revistacienciaagricola/article/view/2327/2374

CIGANA, C. Uso de agrotóxicos no Rio Grande do Sul chega quase ao dobro da média nacional. 2013. Disponível em: https://gauchazh.clicrbs.com.br/geral/ noticia/2013/11/uso-de-agrotoxicos-no-rio-grande-do-sul-chega-a-quase-o-dobroda-media-nacional-4343596.html. Acesso em: 26 mar. 2018.

FERNANDES JUNIOR, O. Fiscais da saúde dos alimentos - empresa de Botucatu é exemplo de certificadora de produtos orgânicos. Desafios do Desenvolvimento - IPEA, Brasília, ano 2, edição 12, 2005. Disponível em: http://desafios.ipea.gov. $\mathrm{br} /$ index . php?option=com_content \&view=article\&id=1417: catid=28\&ltemid=23. Acesso em: 24 mar. 2018

GODINHO, R. F. A gestão de empresas rurais. Milkpoint, São Paulo, jun. 2015. Disponível em: http://www.milkpoint.com.br/radar-tecnico/gerenciamento/agestao-de-empresas-rurais-95522n.aspx. Acesso em: 5 maio 2018.

IFOAM- ORGANICS INTERNATIONAL. The world of organic agriculture. Statistic \& emerging trends. 2017. Disponível em: https://shop.fibl.org/CHde/mwdownloads/ download/link/id/785/?ref=1. Acesso em: 10 abr. 2018.

KARAM, K. F. A mulher na agricultura orgânica e em novas ruralidades. Revista Estudos Femiministas, Florianópolis, SC, v. 12, n. 1, p. 303-20, jan./abr. 2004. DOI http://dx.doi.org/10.1590/S0104-026X2004000100016. Disponível em http:// www.scielo.br/scielo.php?script=sci_arttext\&pid=S0104-026X2004000100016\& Ing=pt\&nrm=iso.

LIMA, P. C.; MOURA, W. M.; SEDIYAMA, M. A. N.; SANTOS, R. H. S.; MOREIRA, C. L. Manejo da adubação em sistemas orgânicos. In: LIMA, P. C.; MOURA, W. M.; VENZON, M.; PAULA JR., T.; FONSECA, M. C. M. (Ed.). Tecnologias para produção orgânica. Viçosa, MG: Unidade Regional EPAMIG Zona da Mata, 2011. p. 69-106. 
LÜDKE, I.; SOUZA, R. B.; BRAGA, D. O.; LIMA, J. L.; REZENDE, F. V. Produção de mudas de pimentão em substrato a base de fibra de coco verde para agricultura orgânica. In: SIMPÓSIO NACIONAL DO CERRADO, 4.; SIMPÓSIO INTERNACIONAL SAVANAS TROPICAIS, 2., Brasília, 2008. Anais [...]. Brasília: Embrapa Cerrados, 2008. p. 01-06.

MALUF, R. S.; REIS, M. C. Conceitos e princípios de segurança alimentar e nutricional. In: ROCHA, C.; BURLANDY, L.; MAGALHÃES, R. (Org.). Segurança alimentar e nutricional - perspectivas, aprendizados e desafios para as políticas públicas. Rio de Janeiro: Fiocruz, 2013. p. 15-42.

MARIANI, C. M.; HENKES, J. A. Agricultura orgânica x agricultura convencional. Soluções para minimizar o uso de insumos industrializados. Revista Gestão \& Sustentabilidade Ambiental, Florianópolis, v. 3, n. 2, p. 315-38, out. 2014/mar. 2015.

MEIRELLES, L. R.; RUPP, L. C. D. (Coord.). Agricultura ecológica - princípios básicos. 2005. Disponível em: http://www.centroecologico.org.br/agricultura.php. Acesso em: 19 mar. 2018

ORGANICS BRASIL. Qual o tamanho do mercado de orgânicos no Brasil? 2015. Disponível em: https://organicsbrasil.org/qual-o-tamanho-do-mercado-deorganicos-no-brasil/. Acesso em: 20 mar. 2018.

ORTIZ, F. Um terço dos alimentos consumidos pelos brasileiros está contaminado por agrotóxicos. Disponível em: http://www.noticias.uol.com.br/saude/ultimasnoticias/redacao/2012/05/01/um-terco-dos-alimentos-consumidos-pelosbrasileiros-esta-contaminado-por-agrotoxicos.htm. Acesso em: 20 mar. 2018.

PENTEADO, S. R. Implantação do cultivo orgânico: planejamento e plantio. 2. ed. Campinas, SP: Via Orgânica, 2012.

PIGNATI, W. Não existe uso seguro de agrotóxicos. 2011. Disponível em: http:// www.ihu.unisinos.br/entrevistas/44972-nao-existe-uso-seguro-de-agrotoxicosentrevista-especialcom-wanderlei-pignati. Acesso em: 10 mar. 2018

SANTOS, I. C.; CARVALHO, L. M. Produção sustentável de hortaliças. Belo Horizonte: EPAMIG, 2013. (Circular Técnica, 182; 5p.).

SANTOS, M. R.; SEDIYAMA, M. A. N.; SALGADO, L. T.; VIDIGAL, S. M.; REIGADO, F. R. Produção de mudas de pimentão em substratos à base de vermicomposto. Bioscience Journal, Uberlândia, MG, v. 26, n. 4, p. 572-8, jul./ago. 2010. 
SANTOS, I. C.; SEDIYAMA, M. A. N.; PEDROSA, M. W. Adubação verde no cultivo de hortaliças. Viçosa, MG: EPAMIG, 2013. (Circular Técnica, 179; 6p.).

SEBRAE. O mercado de orgânicos está aquecido. 2010. Disponível em: http://www. sebrae.com.br/sites/PortalSebrae. Acesso em: 19 mar. 2018.

SEDIYAMA, M. A. N.; SANTOS, M. R.; VIDIGAL, S. M.; SANTOS, I. C.; SALGADO, L. T. Ocorrência de plantas daninhas no cultivo de beterraba com cobertura morta e adubação orgânica. Planta Daninha, Viçosa, MG, v. 28, N. 4, p. 717-25, 2010.

SILIPRANDRI, E. Mulheres e agroecologia: transformando o campo, as florestas e as pessoas. Rio de Janeiro: Ed. UFRJ, 2015.

SILVA, O. S.; SOUZA, R. B.; TAKAMORI, L. M.; SOUZA, W. S.; SILVA, G. P. P. SOUSA, J. M. M. Produção de mudas de pimentão em substratos de coco verde fertirrigadas com biofertilizante em sistema orgânico. Horticultura Brasileira, Brasília, v. 28, n. 2 (Suplemento - CD Rom), p. S2714-S2720, jul. 2010.

SOCIEDADE NACIONAL DE AGRICULTURA (SNA). Mercado de orgânicos cresce o dobro no Brasil. Rio de Janeiro, 2016. Disponível em: http://www.organicsnet. com.br/2016/01/mercado-de-organicos-cresce-o-dobro-no-brasil/. Acesso em: 14 mar. 2018.

SOUZA, I. L. Controle biológico de pragas do pimentão (Capsicum annumm L.) orgânico em cultivo protegido associado a manjericão (Ocimum basilicum L.). 2014. 61p. Dissertação (Mestrado em Entomologia) - Universidade Federal de Lavras (UFLA), Lavras, MG, 2014.

SOUZA, J. L.; RESENDE P. Manual de horticultura orgânica. 2. ed. Viçosa, MG: Aprenda Fácil, 2003. 843p.

VENZON, M.; OLIVEIRA, R. M.; BONOMO, I. S.; PEREZ, A. L.; RODRIGUEZ-CRUZ, F. A.; OLIVEIRA, J. M.; PALLINI, A. Manejo de ácaros-praga em sistemas orgânicos de produção. In: VENZON, M.; OLIVEIRA, R. M.; BONOMO, I. S.; PEREZ, A. L.; RODRIGUEZ-CRUZ, F. A.; OLIVEIRA, J. M.; PALLINI, A. (Ed.). Controle alternativo de pragas e doenças na agricultura orgânica. Viçosa, MG: EPAMIG, 2010. p. 197-211.

YIN, R. K. Estudo de caso: planejamento e métodos. 3. ed. Porto Alegre, RS: Bookman, 2005. 212p. 